Industrial Health, 1975, 13, 81.

\title{
FACTOR-ANALYTICAL OBSERVATION ON DOSE- RESPONSE RELATIONSHIP OF LEAD IN THE OCCUPATIONALLY NON-EXPOSED
}

\author{
Shunichi ARAKI \\ Department of Public Health, Faculty of Medicine, University of Tokyo, \\ Hongo, Bunkyo-ku, Tokyo
}

(Received April 18, 1975)

By the procedure of of factor analysis, the interrelationships of parameters relevant to lead exposure were statistically investigated. The parameters were classified to three groups based on the results of these statistical analysis: the first group contained lead mobilized by CaEDTA and lead in blood, which were considered to be related to the body burden of lead; the second group, ALA-D in erythrocyte, $\delta$-ALA in urine, coproporphyrin in urine and lead in urine, which should be the response to the body burden of lead; the third group, hemoglobin in blood.

It was supported that there might be specific biological reactions to lead in people free from occupational or accidental exposure to lead, though the extent of the reactions was supposed to be much less than that of occupationally-exposed lead workers. The influence of lead to blood hemoglobin level was not found under usual urban environments.

The biological significance seemed to be almost similar between lead in blood and lead mobilization test with the intravenous administration of CaEDTA from the viewpoint of dose-response relationship of lead. The regressions of urinary coproporphyrin and erythrocyte ALA-D activity on lead mobilized by CaEDTA or blood lead were supposed to be nearly linear in people free from occupational lead exposure.

In people without particular exposure to lead, the blood lead levels have been shown to have a logarithmic regression on estimated atmospheric exposure to lead, ${ }^{1)}$ or a semilogarithmic regression on a total absorption of lead, i.e. the amounts of lead absorbed from air, food and water ${ }^{2}$ (Fig. 1). However, the atmospheric lead concentrations are not considered being suitable as a parameter for evaluation of the dose-response relationship of lead in those people, because the amount of lead absorbed from air was calculated to be much less than the amount absorbed through food., ${ }^{3,4}$ Thus, the regression line ${ }^{1,2)}$ can not be applied with confidence to the exposure conditions below the value of approximately $2 \mu \mathrm{g} / \mathrm{m} .{ }^{3,4)}$

Then, the question comes across what parameters are desirable as an indicator of the dose of lead and whether the dose-response relationship of lead is linear or curvilinear in human subjects without the particular exposure to lead. Lately the mobilization yield 


\section{S. ARAKI}

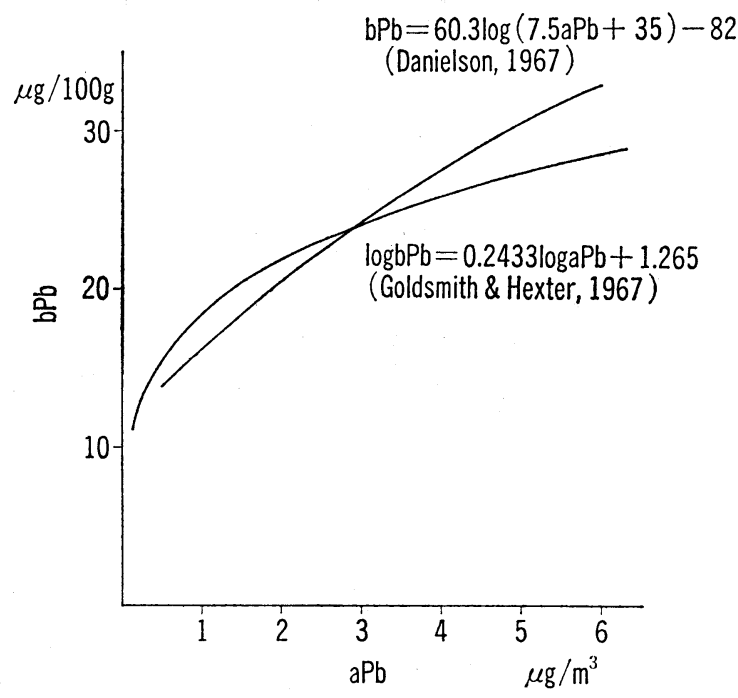

Fig. 1. Dose-response relationship of lead given by two authors.

The $\mathrm{bPb}$ and $\mathrm{aPb}$ mean the lead content in whole blood and atmospheric lead concentrations, respectively. The regression equations are rewritten from the original $\log$ or semilog scale to a normal scale and are shown in the lower range of atmospheric lead concentrations in this diagram. The Danielson's equation was calculated from the original diagram.

of lead by CaEDTA (mobilization test) has been considered being one of the best means of estimating, though indirectly, the active body burden of lead, ${ }^{5 \sim 7)}$ whereas the blood lead levels have still been accepted as the best of the "usual" parameters reflecting the exposure to lead. ${ }^{1,8 \sim 10}$ )

In this report, the author intended to estimate the dose-response relationship of lead in people free from the occupational or accidental exposure to lead based on the knowledge of the interrelationships of parameters relevant to lead exposure.

\section{Subjects ANd Methods}

\section{Subjects}

The subjects consisted of 45 volunteered Japanese adults, 25 men and 20 women: 13 nurses, 10 office workers, 5 assistant nurses, 4 boilermen, 4 divers, 2 physicians, 2 drivers, 2 coalminers, 2 medical technicans and a guardman. All the subjects were under usual urban conditions where the daily average concentration of lead in the atmosphere 


\section{DOSE-RESPONSE RELATIONSHIP OF LEAD IN JAPANESE}

ranged from 0.39 to $3.94 \mu \mathrm{g} / \mathrm{m}^{3}$ with an average of 1.67 for 11 months. ${ }^{11)}$ None of them had ever been exposed to lead occupationally or accidentally.

\section{Collection of samples}

Total amount of urine was collected for $24 \mathrm{hr}$ to measure the urinary contents of lead $(\mathrm{uPb})$ and delta-aminolevulinic acic $(\delta$-ALA). After the collection of spot urine for the measurement of coproporphyrin (Copro.), intravenous infusion of CaEDTA was given to each subject for $1 \mathrm{hr}$ in a dosage of $20 \mathrm{mg}$ per kilogram body weight in $250 \mathrm{ml}$ of $5 \%$ glucose solution. Since the start of infusion, the urine specimens were collected for $2 \mathrm{hr}$ and the following $22 \mathrm{hr}$ to analyse the urinary amounts of lead mobilized by

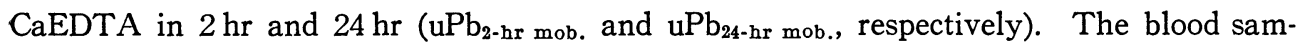
ples were collected about six months after the administration of CaEDTA to investigate the activity of $\delta$-ALA dehydratase in erythrocytes (ALA-D). Further six months had elapsed until the measurements of the lead content in the whole blood ( $\mathrm{bPb}$ ) and the hemoglobin level in blood $(\mathrm{Hb})$.

\section{Analytical methods}

The blood and urinary content of lead before and after the administration of CaEDTA were measured by atomic absorption spectrophotometry (Perkin-Elmer 403); ALA-D, by the method of Weissberg et al. (1971)12); $\delta$-ALA, by the method of Wada et al. (1971) ${ }^{13)}$; Copro., by fluorescence spectrophotometry (Hitachi, MPF-2A); Hb, by the cyanmethemoglobin method; creatinine in the urine, by Jaffe's reaction; specific gravity of urine, by refractometry.

\section{Statistical analysis}

The factor analysis was performed by the use of Hitac 8700 , the University of Tokyo. The factor loadings are extracted by multiplying eigenvectors by the square root of corresponding eigenvalues through the method of principal component analysis. ${ }^{14,15}$ )

\section{RESULTS}

\section{Classification of the parameters indicative of lead exposure by factor analysis}

Thirty nine people, i.e. 21 men and 18 women, who were examined for all the eight parameters are selected for the analysis. The means and standard deviations of the eight parameters are as listed in Table 1 . The urinary contents of $u \mathrm{~Pb}, \delta$-ALA,

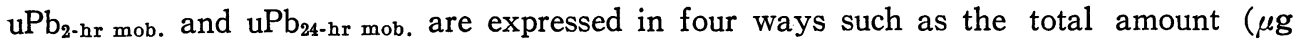
or $\mathrm{mg}$ ), the concentration $(\mu \mathrm{g} / \mathrm{l}$ or $\mathrm{mg} / \mathrm{l}$ ), the corrected concentration to a specific gravity of urine $(\mu \mathrm{g} / l, \mathrm{SG} 1.020$ or $\mathrm{mg} / l, \mathrm{SG} 1.020)$ and the corrected concentration by urinary creatinine content $(\mu \mathrm{g} / \mathrm{g}, \mathrm{Cn}$ or $\mathrm{mg} / \mathrm{g}, \mathrm{Cn})$; the Copro., in the latter three ways. The $\mathrm{bPb}$ is also corrected to $\mathrm{bPb} / \mathrm{Hb}$, which has been reported to have no sexual difference. ${ }^{16}$ )

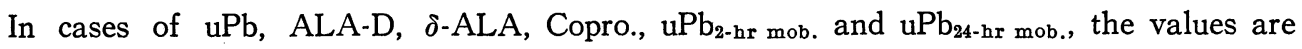
transformed into logarithm to normalize the distribution. In men and women respectively, 


\section{S. ARAKI}

Table 1. Means and standard deviations of parameters related to lead exposure.

\begin{tabular}{|c|c|c|c|c|c|c|c|c|}
\hline & \multirow{2}{*}{\multicolumn{2}{|c|}{ Variables }} & \multicolumn{2}{|c|}{ Men (21) } & \multicolumn{2}{|c|}{ Women (18) } & \multicolumn{2}{|c|}{ Men $\underset{(39)}{\& \text { Women }}$} \\
\hline & & & Mean & $\mathrm{SD}$ & Mean & SD & Mean & $\mathrm{SD}$ \\
\hline \multirow[t]{2}{*}{ 1) } & bPb: & $\mu \mathrm{g} / 100 \mathrm{~g}$ & 12.0 & 4.3 & 7.4 & 2.5 & 9.9 & 4.2 \\
\hline & & $\mu \mathrm{g} / \mathrm{g}, \mathrm{Hb}$ & 0.784 & 0.262 & 0.610 & 0.207 & 0.704 & 0.251 \\
\hline \multirow[t]{3}{*}{ 2) } & $\log \mathrm{uPb}:$ & $\mu \mathrm{g} / 24 \mathrm{hr}$ & 1.115 & 0.397 & 1.066 & 0.217 & 1.092 & 0.323 \\
\hline & & $\mu \mathrm{g} / l$, SG 1.020 & 0.828 & 0.472 & 1.017 & 0.208 & 0.915 & 0.381 \\
\hline & & $\mu \mathrm{g} / \mathrm{g}, \mathrm{Cn}$ & 0.906 & 0.425 & 1.102 & 0.236 & 0.997 & 0.360 \\
\hline 3) & $\log$ ALA-D: & $\mathrm{u}$ & 1.582 & 0.136 & 1.577 & 0.155 & 1.580 & 0.143 \\
\hline \multirow[t]{3}{*}{ 4) } & $\log \delta$-ALA: & $\mathrm{mg} / 24 \mathrm{hr}$ & 0.506 & 0.143 & 0.383 & 0.190 & 0.449 & 0.175 \\
\hline & & $\mathrm{mg} / l$, SG 1.020 & 0.339 & 0.161 & 0.338 & 0.194 & 0.339 & 0.175 \\
\hline & & $\mathrm{mg} / \mathrm{g}, \mathrm{Cn}$ & 0.288 & 0.157 & 0.425 & 0.198 & 0.351 & 0.188 \\
\hline \multirow[t]{2}{*}{ 5) } & log Copro.: & $\mu \mathrm{g} / l$, SG 1.020 & 1.663 & 0.320 & 1.687 & 0.197 & 1.674 & 0.267 \\
\hline & & $\mu \mathrm{g} / \mathrm{g}, \mathrm{Cn}$ & 1.573 & 0.307 & 1.691 & 0.238 & 1.627 & 0.280 \\
\hline 6) & $\mathrm{Hb}:$ & $\mathrm{g} / \mathrm{d} l$ & 15.3 & 1.1 & 12.3 & 1.0 & 13.9 & 1.9 \\
\hline \multirow[t]{3}{*}{ 7) } & $\log \mathrm{uPb}_{2-\mathrm{hr}}$ mob.: & $\mu \mathrm{g} / 2 \mathrm{hr}$ & 1.047 & 0.204 & 0.899 & 0.194 & 0.978 & 0.211 \\
\hline & & $\mu \mathrm{g} / l, \mathrm{SG} 1.020$ & 1.841 & 0.171 & 1.839 & 0.184 & 1.840 & 0.175 \\
\hline & & $\mu \mathrm{g} / \mathrm{g}, \mathrm{Cn}$ & 1.934 & 0.182 & 1.980 & 0.182 & 1.956 & 0.181 \\
\hline \multirow[t]{3}{*}{ 8) } & $\log \mathrm{uPb}_{24-\mathrm{hr}}$ mob.: & $\mu \mathrm{g} / 24 \mathrm{hr}$ & 1.951 & 0.175 & 1.679 & 0.185 & 1.826 & 0.224 \\
\hline & & $\mu \mathrm{g} / l$, SG 1.020 & 1.739 & 0.184 & 1.614 & 0.195 & 1.681 & 0.197 \\
\hline & & $\mu \mathrm{g} / \mathrm{g}, \mathrm{Cn}$ & 1.725 & 0.187 & 1.711 & 0.191 & 1.719 & 0.186 \\
\hline
\end{tabular}

Number of cases, examined, is shown in parentheses. SD means standard deviation; SG, specific gravity of urine; $\mathrm{Cn}$, creatinine.

the eight parameters are analysed. In men and women combined, $\mathrm{bPb} / \mathrm{Hb}$ is selected instead of $\mathrm{bPb}$ which is omitted together with $\mathrm{Hb}$ because of highly significant sexual difference $(\mathrm{p}<0.001)$. To check the reproducibility of the analysis, the three expressions

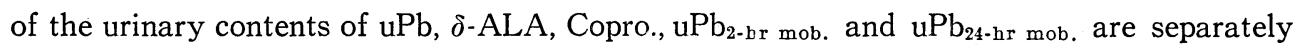
analysed together with other parameters in men, women, and men and women combined.

Correlation matrices are shown in Table 2. Each correlation matrix contains two sets of submatrix where the urinary contents of $\mathrm{uPb}, \delta$-ALA, Copro., $\mathrm{uPb}_{2-\mathrm{hr} \text { mob. and }}$ $\mathrm{uPb}_{24-\mathrm{hr} \text { mob. }}$ are expressed in two ways, i.e. the corrected concentration by urinary creatinine and the corrected concentration to a specific gravity of urine.

As is shown in Table 3, the proportion of the first principal component to the total variance is from 28 to $33 \%$ in men, women, and men and women combined; the second component, 17 to $21 \%$; the third, 14 to 16 . Sixty three to sixty six per cent of the information is involved in the three components. And up to the third component, the eigenvalues are beyond 1.0. So, the extraction of factors is stopped in the third component.

Factor matrices and a plain consisting of the first factor (FC 1) and the second factor (FC 2) of men and women combined are shown in Table 4 and Fig. 2, respectively. The analysis of eight parameters including $\mathrm{bPb}$ and $\mathrm{Hb}$ in women is shown in Fig. 3. 


\section{DOSE-RESPONSHIP OF LEAD IN JAPANESE}

Table 2. Correlation matrices of parameters related to lead exposure.

A. Men $(n=21)$

\begin{tabular}{|c|c|c|c|c|c|c|c|c|}
\hline 1) & 2) & 3) & 4) & 5) & 6) & 7) & 8) & Correlation coefficient \\
\hline 1.000 & 0.160 & 0.354 & 0.221 & $0.463 \dagger$ & -0.320 & 0.041 & 0.258 & 1) $\mathrm{bPb}$ \\
\hline-0.031 & 1.000 & 0.295 & -0.049 & 0.123 & -0.285 & 0.157 & 0.253 & 2) $\log \mathrm{uPb}$ \\
\hline 0.354 & 0.091 & 1.000 & 0.032 & 0.048 & -0.333 & 0.151 & 0.297 & 3) $-\log$ ALA-D \\
\hline 0.247 & -0.187 & 0.192 & 1.000 & $0.45 z t$ & -0.207 & 0.283 & 0.169 & 4) $\log \delta$-ALA \\
\hline $0.472 \dagger$ & 0.377 & 0.085 & 0.317 & 1.000 & -0.383 & 0.408 & 0.331 & 5) $\log$ Copro \\
\hline-0.320 & -0.223 & -0.333 & -0.372 & -0.333 & 1.000 & -0.194 & 0.139 & 6) $-\mathrm{Hb}$ \\
\hline 0.048 & 0.147 & 0.426 & -0.104 & 0.321 & -0.095 & 1.000 & $0.455 \dagger$ & 7) $\log \mathrm{uPb}_{2-\mathrm{hr} \text { mob. }}$ \\
\hline 0.127 & 0.025 & 0.307 & -0.020 & 0.257 & 0.114 & $0.499 \dagger$ & 1.000 & 8) $\log \mathrm{uPb}_{24-\mathrm{hr} \text { mob. }}$ \\
\hline
\end{tabular}

B. Women $(n=18)$

\begin{tabular}{|c|c|c|c|c|c|c|c|c|}
\hline 1) & 2) & 3) & 4) & 5) & 6) & 7) & 8) & Correlation coefficient \\
\hline 1.000 & 0.096 & -0.132 & 0.094 & 0.166 & -0.025 & 0.390 & 0.336 & 1) $\mathrm{bPb}$ \\
\hline 0.159 & 1.000 & 0.135 & 0.311 & 0.257 & 0.131 & 0.284 & 0.253 & 2) $\log \mathrm{uPb}$ \\
\hline-0.132 & 0.088 & 1.000 & 0.462 & 0.195 & 0.189 & 0.026 & -0.338 & 3) $-\log$ ALA-D \\
\hline 0.121 & 0.159 & 0.383 & 1.000 & 0.287 & -0.083 & 0.221 & 0.260 & 4) $\log \delta$-ALA \\
\hline-0.102 & -0.020 & 0.107 & 0.193 & 1.000 & 0.459 & 0.118 & 0.184 & 5) log Copro. \\
\hline-0.025 & 0.120 & 0.189 & -0.045 & 0.013 & 1.000 & 0.238 & 0.119 & 6) $-\mathrm{Hb}$ \\
\hline $0.555 \dagger$ & 0.288 & 0.110 & 0.205 & -0.168 & 0.250 & 1.000 & $0.717 \mathrm{itt}$ & 7) $\log \mathrm{uPb}_{2-\mathrm{hr}}$ mob. \\
\hline 0.404 & 0.285 & -0.284 & 0.408 & 0.032 & 0.049 & 0.420 & 1.000 & 8) $\log \mathrm{uPb}_{24-\mathrm{hr} \text { mob. }}$ \\
\hline
\end{tabular}

C. Men and women $(n=39)$

\begin{tabular}{|c|c|c|c|c|c|c|c|}
\hline 1) & 2) & 3) & 4) & 5) & 6) & 7) & Correlation coefficient \\
\hline 1.000 & -0.016 & 0.102 & -0.025 & 0.216 & 0.118 & 0.304 & 1) $\mathrm{bPb} / \mathrm{Hb}$ \\
\hline-0.117 & 1.000 & 0.222 & 0.171 & 0.206 & 0.217 & 0.223 & 2) $\log \mathrm{uPb}$ \\
\hline 0.102 & 0.084 & 1.000 & 0.255 & 0.110 & 0.091 & 0.019 & 3) $-\log$ ALA-D \\
\hline 0.136 & -0.070 & 0.295 & 1.000 & 0.411 th & 0.277 & 0.186 & 4) $\log \delta$-ALA \\
\hline 0.226 & 0.302 & 0.090 & 0.255 & 1.000 & 0.309 & 0.255 & log Copro. \\
\hline 0.256 & 0.167 & 0.265 & 0.058 & 0.140 & 1.000 & $0.566 \mathrm{ttt}$ & 6) $\log \mathrm{uPb}_{2-\mathrm{hr}} \mathrm{mob}$ \\
\hline $0.338 \dagger$ & 0.004 & 0.002 & 0.192 & 0.148 & $0.437+t$ & 1.000 & 7) $\log u \mathrm{~Pb}_{24-\mathrm{hr} \text { mob. }}$ \\
\hline
\end{tabular}

Urinary contents of $\mathrm{uPb}, \delta$-ALA, Copro., $\mathrm{uPb}_{2-\mathrm{hr}}$ mob., and $\mathrm{uPb}_{24-\mathrm{hr}} \mathrm{mob}$. are expressed in the corrected concentration by urinary creatinine content and the corrected concentration to a specific gravity of urine above and below the diagonal, respectively. A dagger ( $\dagger$ ), a double dagger $(t)$, and a triple dagger ( $t+t)$ indicate statistical significance at $5 \%, 1 \%$ and $0.1 \%$ levels, respectively. 


\section{S. ARAKI}

Table 3. Eigenvalues and cumulative proportion of total variance.

\begin{tabular}{l|ccc|ccc}
\hline \multirow{2}{*}{ Principal component } & \multicolumn{3}{|c|}{ Type 1 } & \multicolumn{4}{c}{ Type 2 } \\
\cline { 2 - 4 } \cline { 5 - 7 } & CP 1 & CP 2 & CP 3 & CP 1 & CP 2 & CP 3 \\
\hline Men: & 2.67 & 1.34 & 1.23 & 2.49 & 1.59 & 1.22 \\
$\quad$ Eigenvalue & 0.33 & 0.50 & 0.66 & 0.31 & 0.51 & 0.66 \\
$\quad$ Cumulative proportion & & & & & & \\
\hline Women: & 2.43 & 1.66 & 1.12 & 2.28 & 1.51 & 1.21 \\
$\quad$ Eigenvalue & 0.30 & 0.51 & 0.65 & 0.28 & 0.47 & 0.63 \\
$\quad$ Cumulative proportion & & & & & & \\
\hline Men and women combined: & 2.29 & 1.23 & 0.99 & 2.02 & 1.24 & 1.13 \\
$\quad$ Eigenvalue & 0.33 & 0.50 & 0.64 & 0.29 & 0.47 & 0.63 \\
$\quad$ Cumulative proportion &
\end{tabular}

Urinary contents of $\mathrm{uPb}, \delta$-ALA, Copro., $\mathrm{uPb}_{2-\mathrm{hr}}$ mob., and $\mathrm{uPb}_{24-\mathrm{hr}}$ mob. are expressed in the corrected concentration by urinary creatinine content and the corrected concentration to a specific gravity of urine in Type 1 and Type 2, respectively.

Table 4. Factor matrices of men and women combined.

\begin{tabular}{|c|c|c|c|c|c|c|}
\hline \multirow{2}{*}{ Factor loadings } & \multicolumn{3}{|c|}{ Type 1} & \multicolumn{3}{|c|}{ Type 2} \\
\hline & FC 1 & $\mathrm{FC} 2$ & FC 3 & FC 1 & $\mathrm{FC} 2$ & $\mathrm{FC} 2$ \\
\hline 1) $\mathrm{bPb} / \mathrm{Hb}$ & 0.35 & 0.49 & -0.74 & 0.59 & 0.42 & 0.09 \\
\hline 2) $\log \mathrm{uPb}$ & 0.48 & -0.34 & 0.20 & 0.21 & -0.82 & 0.35 \\
\hline 3) $-\log$ ALA-D & 0.33 & -0.60 & -0.51 & 0.44 & -0.22 & -0.55 \\
\hline 4) $\log \delta$-ALA & 0.59 & -0.45 & 0.08 & 0.49 & 0.02 & -0.68 \\
\hline log Copro. & 0.67 & -0.09 & -0.10 & 0.54 & -0.46 & -0.01 \\
\hline $\log \mathrm{uPb}_{2-\mathrm{hr}}$ mob. & 0.73 & 0.23 & 0.31 & 0.68 & 0.03 & 0.34 \\
\hline $\log \mathrm{uPb}_{24-\mathrm{hr}}$ mob. & 0.70 & 0.49 & 0.17 & 0.66 & 0.36 & 0.35 \\
\hline
\end{tabular}

Urinary contents of $\mathrm{uPb}, \delta$-ALA, Copro., $\mathrm{uPb}_{2}-\mathrm{hr}$ mob., and $\mathrm{uPb}_{24-\mathrm{hr}}$ mob. are expressed in the corrected concentration by urinary creatinine content and the corrected concentration to a specific gravity of urine in Type 1 and Type 2 , respectively.

As is obvious from Figs. 2 and 3, the parameters can be classified to three groups. The first group contains $\mathrm{uPb}_{24-\mathrm{hr} \text { mob., }} \mathrm{uPb}_{2-\mathrm{hr}}$ mob., $\mathrm{bPb}$ and $\mathrm{bPb} / \mathrm{Hb}$; the second group, ALA-D, $\delta$-ALA, Copro. and $\mathrm{uPb}$; the third, $\mathrm{Hb}$. The first group is considered to be related to the body burden of lead; the second group, the response to the body burden of lead.

\section{2. "Dose-response relationship"}

The dose-response relationship of lead is estimated from the following standpoint: The relationships between the parameters considered to be reflecting the body burden of

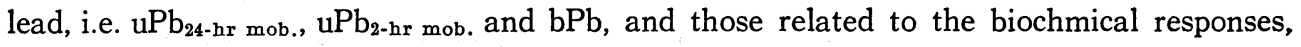
i.e. ALA-D, $\delta$-ALA, Copro. and Hb. 


\section{DOSE-RESPONSE RELATIONSHIP OF LEAD IN JAPANESE}

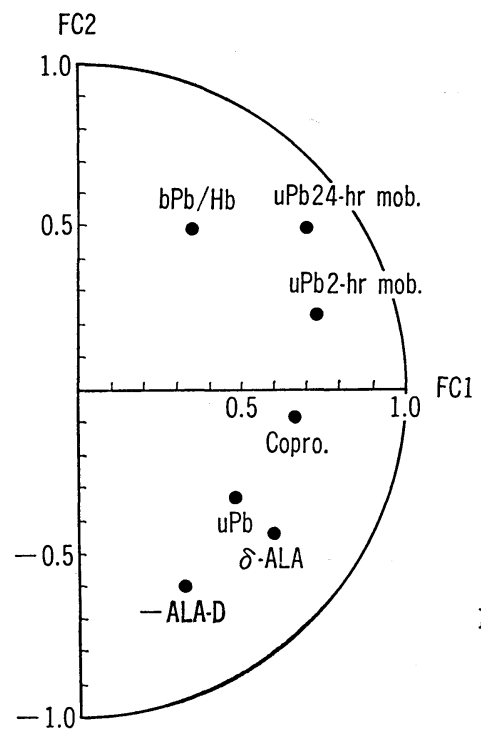

Fig. 2. A plain consisting of the first and second factors in type 1 of men and women combined.
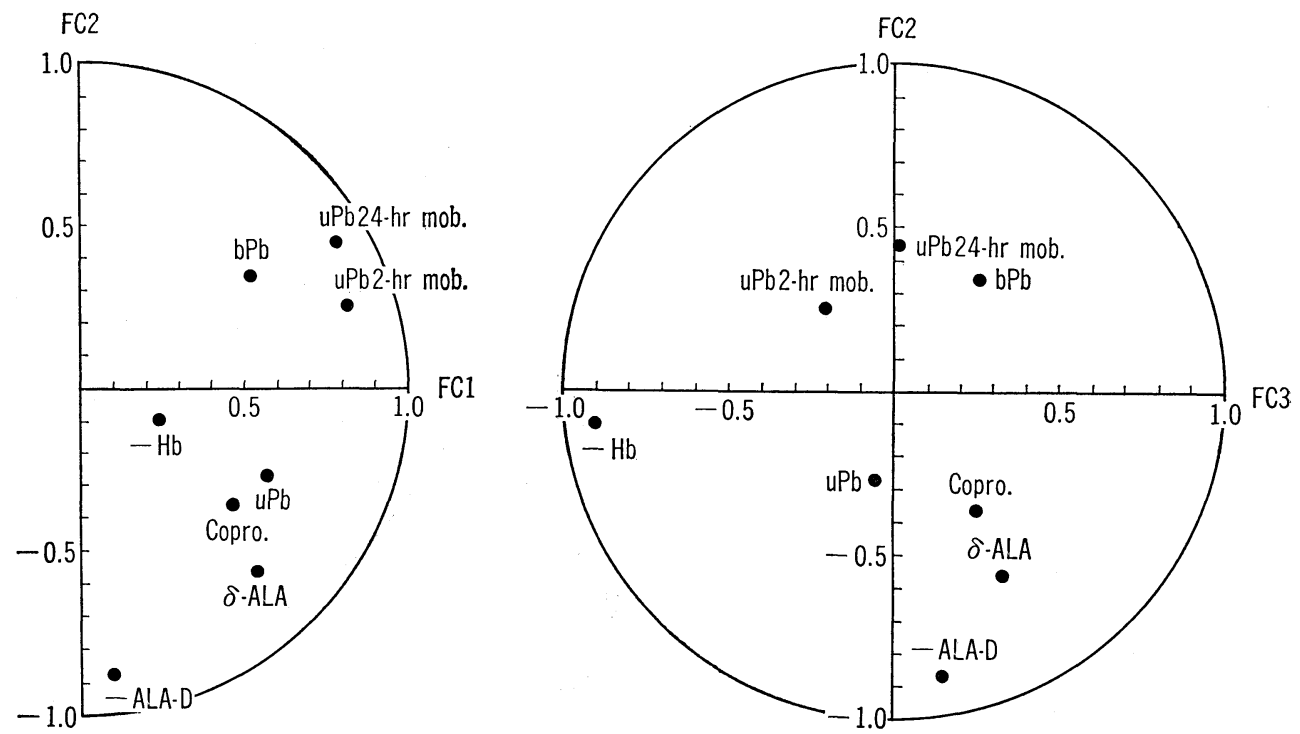

Fig. 3. A plain consisting of the first, second and third factors in type 1 of women.

(a) The first factor (FC 1) and the second factor (FC 2)

(b) The second factor (FC 2) and the third factor (FC 3) 


\section{S. ARAKI}
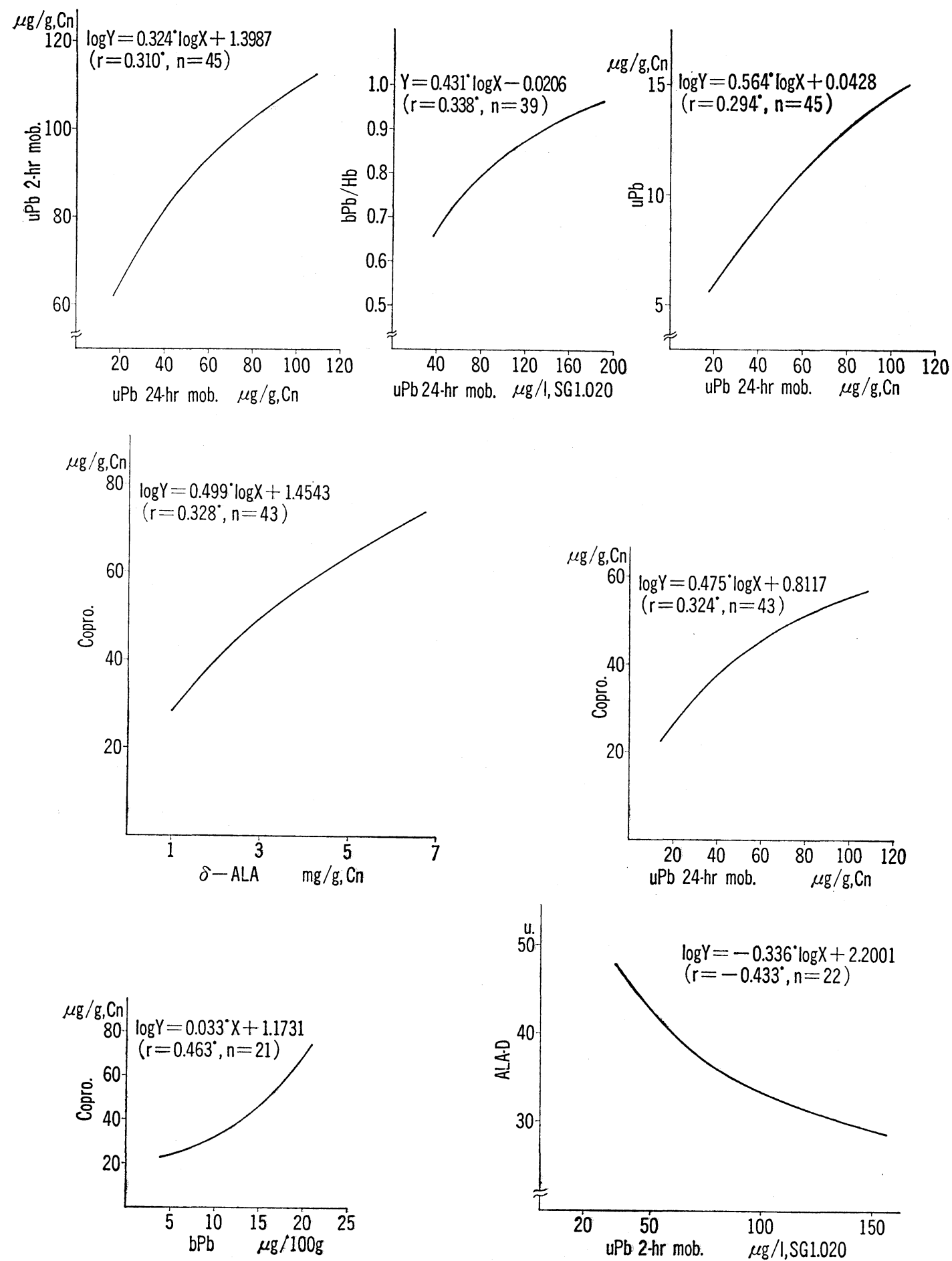

Fig. 4. Regression equations among seven parameters related to lead exposure.

Regression equations are obtained from men and women combined except for the last two from men. An asterisk $(*)$ indicates statistical significance at $5 \%$ level. 


\section{DOSE-RESPONSE RELATIONSHIP OF LEAD IN JAPANESE}

As was shown in the previous report of the present author, the correlation matrices of all the parameters disclosed small in the extent, but significant correlation between the parameters except for Hb. ${ }^{3)}$

The regression equations obtained previously and concomitantly in the process of foctor analysis are shown in Fig. 4 in a normal scale. As is clear from the figure, $\mathrm{uPb}_{2-\mathrm{hr} \text { mob., }} \mathrm{bPb} / \mathrm{Hb}$ and $\mathrm{uPb}$ have nearly linear regression curves on $\mathrm{uPb}_{24-\mathrm{hr} \text { mob. The }}$ same statement holds true for the relationship between $\delta$-ALA and Copro.. As to the "dose-response relationship", Copro. has nearly linear regression curves on $\mathrm{uPb}_{24-\mathrm{hr}}$ mob. and $\mathrm{bPb}$. ALA-D has a slightly concave regression on $\mathrm{uPb}_{2-\mathrm{hr}}$ mbo.

\section{Relationships between three expressions of urinary contents}

Through the procedure of factor analysis, all the three expressions of urinary contents of $\mathrm{uPb}, \delta$-ALA, Copro., $\mathrm{uPb}_{2-\mathrm{hr}}$ mob. and $\mathrm{uPb}_{24-\mathrm{hr}}$ mob. are analysed concurrently with $\mathrm{bPb} / \mathrm{Hb}$ and ALA-D in men and women combined. The cumulative proportion of total variance is 56 per cent up to the third component, in which the extraction of factors is stopped.

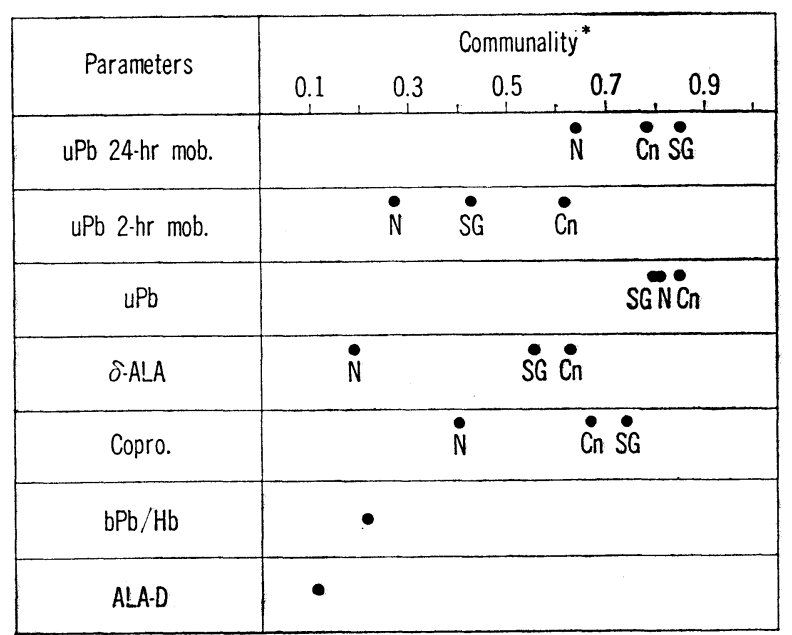

Fig. 5. Relationships among three expressions of urinary contents related to lead exposure.

*: the communality has been obtained by summing up the square of factor loadings of the first, second and third factors through factor analysis.

Cn: corrected concentration by urinary creatinine content.

SG: corrected concentration to a specific gravity of urine.

N: not-corrected concentration. 


\section{S. ARAKI}

As is obvious from Fig. 5, the most amount of information of $\mathrm{uPb}_{2-\mathrm{hr}}$ mob., $\mathrm{uPb}$ and $\delta$-ALA is involved in the corrected concentration by creatinine content among the three

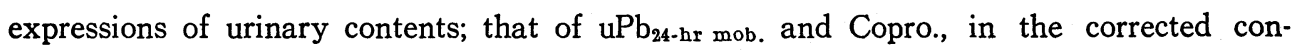
centration to a specific gravity of urine; the least amount of information is involved in the not-corrected concentration except for $\mathrm{uPb}$. Owing to the influence of multiple variables of other parameters which are closely related, the communality of $\mathrm{bPb} / \mathrm{Hb}$ and ALA-D is smaller in extent in this analysis than that in the above analysis (Fig. 2) where the single expression of each parameter is used as a variable.

\section{Discussion}

The factor analysis of parameters relevant to the exposure to lead was reported in occupationally exposed lead workers by Suzuki, S. and Suzuki, T. (1974).17) They applied the method to two sets of "lead exposure indicators" i.e., uPb, $\delta$-ALA, Copro., Hb et al.; and found that the indicators had a complex structure after the discontinuation of the exposure and that Copro. had a noticeably different character from other indicators. Their results were not consistent with those obtained by the present author, i.e., Copro. was classified to the same group as $\delta$-ALA and $\mathrm{uPb}$ in this study. The present author considers that any influence other than lead, e.g. liver diseases, ${ }^{18)}$ should be evaluated in their study. In this connection, the present author is preparing a report on lead workers where the character of Copro. is very similar to that of $\delta$-ALA.19, 22)

Following points were elucidated by the present study:

Firstly, the existence of small in extent, but significant biological reactions to lead in the occupationally non-exposed people which was suggested by Hernberg and Nikkanen $(1970)^{20)}$ and the present author (1973), ${ }^{3)}$ was supported by the present analysis, which separated the parameters related to the body burden of lead (dose-factor) from those related to the response to lead (response-factor).

Secondly, the lead under usual urban environments was not considered to influence to the hemoglobin level.

Thirdly, the behaviour of the blood lead level was almost consistent with that of the mobilization test. This finding shows that both the parameters have biologically close character in terms of the dose-response relationship of lead.

Fourthly, the urinary lead content was classified to the group indicative of the response to lead, together with ALA-D, $\delta$-ALA and Copro., rather than to the group relevant to the dose-factor. This finding may signify that the urinary lead excretion is under great influence of daily exposure to lead in the usual, non-occupational environments, e.g., food and air.

Fifthly, Copro. had significant correlations with parameters related to the body burden of lead, with which $\delta$-ALA had not. This result coincides with a prospective study by Tola et al. (1973), ${ }^{21)}$ contrary to that in most publications on lead workers.

Sixthly, the responses of urinary coproporphyrin content and erythrocytes $\delta$-ALA 


\section{DOSE-RESPONSE RELATIONSHIP OF LEAD IN JAPANESE}

dehydratase activity to deposit of lead, if present, were supposed to be nearly linear in people without the particular exposure.

Lastly, it was shown that the corrected concentration by creatinine content or that to a specific gravity of urine reflected the exposure level of lead better than the notcorrected concentration in people free from occupational lead exposure.

The dose-response relationship of lead in human beings should be investigated in the whole range of the "active" body burden of lead. So, the present results will be compared with those of occupationally exposed lead workers in the author's next paper. ${ }^{22)}$

\section{ACKNOWLedgement}

The author wishes to express his thanks to Prof. H. Katsunuma, University of Tokyo, Prof. T. Suzuki, Tohoku University, and Dr. K. Ushio, Tokyo Labour Accident Hospital, for their encouragement and valuable suggestions. Thanks are also due to Dr. H. Yanai, University of Tokyo, and Mrs. K. Araki for their advice and assistance in factor analysis.

This paper was presented at the 32nd Annual Meeting of the Japanese Society of Public Health, 1973.

\section{REFERENCES}

1) Goldsmith, J.R. and Hexter, A.C. (1967). Science, 158, 132.

2) Danielson, L. (1970). Gasoline Containing Lead, Ecological Research Committee Bulletin No. 6, p. 1. Swedish Natural Science Research Council, Stockholm.

3) Araki, S. (1973). Ind. Health, 11, 203.

4) National Research Council (1972). Lead, Airborne Lead in Perspective, p. 62. National Academy of Sciences, Washington, D.C..

5) Teisinger, J., Prerovska, I., Sedivec, V., Flek, J. and Roth, Z. (1969). Int. Arch. Gewerbepathol. Gewerbehyg., 25, 240.

6) Teisinger, J. (1971). Arch. Environ. Health, 23, 280.

7) Kehoe, R.A. (1971). Editorial comment in Zielhuis, R.L. (1971). Arch. Environ. Health, 23, 299 .

8) Kehoe, R.A., (1964). Arch. Environ. Health, 8, 235.

9) Hernberg, S., Nikkanen, J., Mellin, G. and Lilius, H. (1970). Arch. Environ. Health, 21, 140 .

10) Zielhuis, R.L. (1971). Arch. Environ. Health, 23, 299.

11) Nagata, M., Hirono, T., Yamazaki, H., Asakino, K., Nakano, K. and Ohira, T. (1972). Annual Report of Tokyo Metropolitan Research Institute for Environmental Protection, 3rd ed., p. 3. Teikoku-Chiho-Gyosei-Gakkai, Tokyo. (in Japanese)

12) Weissberg, J.B., Lipschutz, F. and Oski, F.A. (1971). New Engl. J. Med., 284, 565.

13) Wada, O., Toyokawa, K., Urata, G., Yano, Y. and Nakao, K. (1969). Brit. J. Ind. Med., 26, 240 . 


\section{S. ARAKI}

14) Software Works, Hitachi Ltd. (1972). Haitakku 8700 HSAP Tokei Keisan Raiburari (Hitac 8700 Hitachi Statistical Analysis Program), p. 208. Hitachi Ltd., Yokohama. (in Japanese)

15) Okuno, T., Kume, H., Haga, T. and Yoshizawa, T. (1972). Tahenryo Kaiseki Ho (Multivariate Analysis), p. 167. Nikkagiren shuppansha, Tokyo. (in Japanese)

16) Okutani, H. and Harada, A. (1973). Abstracts of Presentations at 46th Annual Meeting of Japan Association of Industrial Health., p. 304. (in Japanese)

17) Suzuki, S. and Suzuki, T. (1974). Ind. Health 12, 37.

18) Nesbitt, S. and Snell, A.M. (1942). Arch. Int. Med., 69, 573.

19) Araki, S., Ushio, K. and Katsunuma, H. (1974). Jap. J. Ind. Health, 16, 345. (in Japanese)

20) Hernberg, S. and Nikkanen, J. (1970). Lancet, No. 7637, 63.

21) Tola, S., Hernberg, S., Asp, S. and Nikkanen, J. (1973). Brit. J. Ind. Med., 30, 134.

22) Araki, S. (1975). Ind. Health, 13, in press. 